\title{
APPLICATION OF COGNITIVE-BEHAVIORAL THERAPY IN PATIENTS WITH UNCONTROLLED BRONCHIAL ASTHMA DUE TO EXCESS BODY WEIGHT AND OBESITY
}

DOI: 10.36740/WLek202001126

\author{
Yana I. Bazhora \\ ODESA NATIONAL MEDICAL UNIVERSITY, ODESA, UKRAINE
}

\begin{abstract}
The aim: The aim of our study was to determine the effect of CBT in patients with uncontrolled BA against the background of excess body weight and obesity.

Materials and methods: By the study design there were examined 78 patients who had a primary diagnosis of uncontrolled BA.

Results: The patients in the main group had significant positive dynamics regarding a number of AQLQ questionnaires, namely emotions, activity, overall quality of life ( $\mathrm{p} \leq 0.05$ ). These patients also had a positive dynamics in overcoming anxiety-depressive disorders, namely from $10.23 \pm 0.81$ points anxiety disorders scored $7.65 \pm 0.98$ points after (BT, and depressive changes - from $10.01 \pm 0.79$ points to $7.69 \pm 0.67$ points by the HADS scale $(p \leq 0.05)$.

Conclusions: The use of CBT has a positive effect on certain indices of the AQLQ questionnaire $(p \leq 0.05)$ and has a positive effect on the psychological state of the patient, namely, it reduces the manifestations of anxiety and depression $(p \leq 0.05)$ in patients with uncontrolled asthma as well as improves the course of uncontrolled asthma by a number of indices, namely reducing the frequency of use of short-acting $\beta$-2-agonists, nocturnal symptoms of asthma, the amount of oral and peroral steroids.
\end{abstract}

KEY WORDS: bronchial asthma, cognitive - behavioral therapy (CBT), EBW, anxiety-depressive disorders (ADD)

Wiad Lek. 2020;73(1):134-138

\section{INTRODUCTION}

Bronchial asthma (BA) is a chronic respiratory disease characterized by the manifestations of such symptoms as wheezing, shortness of breath, chest tightness, which vary greatly over time in different people [1]. Recent studies have suggested that more than 334 million people on the Earth suffer from asthma, and it has been found that the cost of asthma is one of the largest in the world among non-communicable diseases [2].

At the same time, there are a number of diseases that have a similar pattern, such as shortness of breath, chest tightness, coughing, palpitations, inability to complete the phrase, etc. In our opinion, the most common among them in the adult population are anxiety (AD) and depressive (DD) disorders, which may have a character a comorbid disease in patients with asthma, potentiating more severe and less controlled asthma $[3,4]$.

According to a number of studies, patients with asthma have a higher rate of $\mathrm{AD}$ and $\mathrm{DD}$ than in the population [5]. It is established that depending on the severity of the course $22-45 \%$ of patients have comorbid pathology in the form of BA against the background of $\mathrm{DD}$, and $\mathrm{AD}$ and / or from 6.5 to $26 \%$ of patients have panic disorder (PD) $[6,7,8]$. According to GINA 2016, the presence of psychological disorders in patients with asthma is associated with a more severe asthma and more visits to the hospital, especially for people from deprived socio-economic and ethnic backgrounds [2].
Another pressing issue for patients with asthma is the presence of excess body weight (EBW) or obesity, which is also an aggravating factor in controlling the disease. Patients with EBW or obesity have been found to have a low disease control and poor response to traditional therapy $[9,10,11]$.

Patients with insufficient control and comorbid diseases, mentioned above, have been found to use fast-acting bronchodilator (FABD) more often than patients with BA alone [12]. The use of FABD has many side effects, reduces the response to basic therapy and, even leads to an increase in lethal events among the population of patients with BA. At the same time, it has been established that the presence of patients with $\mathrm{BA}$ with $\mathrm{AD}$ or $\mathrm{DD}$ leads to poor keeping basic therapy and such patients more often do not keep the recommended lifestyle (for example: quitting smoking, avoiding contact with allergens, etc.) $[13,14]$.

Recent studies indicate a positive effect of cognitive-behavioral therapy in the treatment of patients with asthma [15].

Cognitive - behavioral therapy (CBT) is a complex of psychotherapeutic measures that includes behavioral and cognitive therapies. The cognitive approach is based on the assumption that psychological problems and neuro-psychiatric disorders are recognized as illogical inappropriate thoughts and beliefs of a person, as well as dysfunctional stereotypes of his thinking, which can be solved if changed. The behavioral approach, based on the theory of behaviorism, involves changes in the human behavior by encouraging and reinforcing desirable behavior forms and absence of re- 


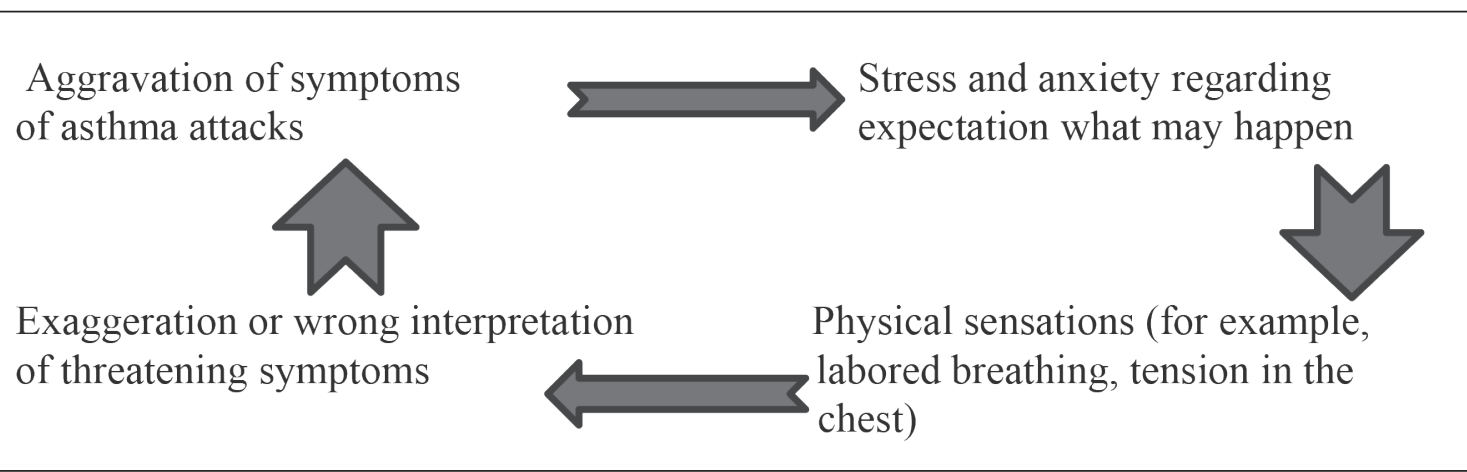

Fig 1. The vicious circle of patients' concerns as to asthma

inforcement of undesirable forms. In our case, cognitive-behavioral therapy is a treatment-and-preventive measure that is a cognitive tool of the patient's self-influence [16].

In the context of chronic diseases, and BA is precisely such a disease, a person is confronted with certain aspects of the disease that can be troublesome or difficult to cope with by himself, which in turn leads to physiological reactions that worsen the course of the underlying disease. CBT aims at breaking the vicious circle of patients with asthma (Fig. 1).

Concerning the relevance of CBT in patients with EBW or obesity, we have the following data: CTC has traditionally been considered as one of the best treatments for EBW or obesity [17]. In some publications, this method is considered as the first-line treatment among psychological approaches [18]. Although data suggest positive results, some studies indicate that this psychotherapy does not necessarily lead to successful loss of excess body weight [19] in comparison with placebo [20,21].

In his study DalleGrave with co-authors described a typical CBT protocol, which reported a set of procedures needed to eliminate obstacles to losing and maintaining a patient's body weight [22].

As early as 2004, the National Institute of Clinical Excellence recommended to use $\mathrm{CBT}$ in the treatment of patients with EBW or obesity with an A degree of evidentiality.

Taking into account all of the above, there is a need to find additional methods in the treatment of patients with asthma against the background of EBW or obesity, as we believe, this may be alongside with basic cognitive-behavioral therapy, namely in patients with uncontrolled overweight and obesity.

\section{THE AIM}

The aim of our study was to determine the effect of using cognitive-behavioral therapy in patients with uncontrolled course of asthma in presence of EBW and obesity.

\section{MATERIALS AND METHODS}

The study was conducted on the basis of the Department of Family Medicine and General Practice. According to he study design there were examined 78 patients who had a primary diagnosis of uncontrolled BA. The study involved adults from 19 to 57 years of age. The patients were divided into groups, namely the main group included $39(50.00 \%)$ patients who were offered CBT and 39 patients (50.00\%) who refused CBT and formed a comparison group that received only basic treatment.

In the development of CBT, we were guided by certain principles that aided in the work with the patient, namely: CBT is based on the formulation of the patient's problem and the individual conceptualization of each patient within a cognitive approach; CBT involves creating a strong therapeutic alliance between the physician and the patient; special attention in $\mathrm{CBT}$ is given to the cooperation and active involvement of the physician in assisting the patient; $\mathrm{CBT}$ is aimed at the result and focused on issues that are fundamental to the clinical course of the underlying disease; first of all, CBT emphasizes the current concern of the patient today; CBT is first and foremost an educational therapy, its purpose is to teach the patient to be a doctor for himself; CBT should be time-limited, in our case it was 15 sessions; CBT sessions should be structured; CBT teaches patients to identify, evaluate, and respond to their dysfunctional thoughts and beliefs; CBT uses a number of techniques to help change mode of thoughts, mood and behavior.

CBT developed by us included, as indicated above, 15 sessions: the first six sessions were twice a week, then six sessions were once a week, the last 3 sessions were once every two weeks. That is only 15 weeks of therapy. Then, at the request and need of the patient, sessions were offered once every three months during the year.

The session was structured and had the following parts: introductory part (mood check, short discussion of the last week, collaborative formation of the session plan), middle part (discussion of homework, current problems according to the plan, new homework definition, summarizing), and concluding part (receiving feedback).

To establish positive dynamics in the course of the underlying disease, namely BA, the following criteria were offered to our patients: quality of life assessment (AQLQ (quality of life in asthma)), symptom control (the number of FABD used per week, the amount of nocturnal symptoms, response to the baseline therapy, asthma control (AST test), use of oral and peroral steroids), changes in $\mathrm{AD}$ and $\mathrm{DD}$ were diagnosed using the Hospital Alarm and Depression Scale (HADS). These diagnostic criteria were applied in the first, eighth and fifteenth sessions.

Statistical analysis was carried out by conventional methods of variational statistics. Reliability was assessed by Student's $t$ test. The differences were considered reliable at the significance level of $\mathrm{p} \leq 0.05$. Correlation was established 
Table I. AQLQ quality of life assessment at the first visit in patients with uncontrolled bronchial asthma

\begin{tabular}{ccc}
\hline \multirow{2}{*}{ Scale } & \multicolumn{2}{c}{ Groups } \\
\cline { 2 - 3 } & Main group & Comparison group \\
\hline Activity & $3.7 \pm 0.1$ & $3.6 \pm 0.2$ \\
\hline Symptoms & $3.5 \pm 0,3$ & $3.5 \pm 0,1$ \\
\hline Emotions & $3.6 \pm 0.1$ & $3.5 \pm 0.5$ \\
\hline Environment & $3.4 \pm 0.2$ & $3.4 \pm 0.3$ \\
\hline General life quality & $3.5 \pm 0.1$ & $3.5 \pm 0.2$ \\
\hline
\end{tabular}

Note: ${ }^{*} p<0.05$

Table II. The disease course and symptom control at the first visit in patients with uncontrolled bronchial asthma

\begin{tabular}{ccc} 
Criterium & \multicolumn{2}{c}{ Group } \\
\cline { 2 - 3 } Comparison \\
\hline Use of FABD per week & Main & $8.5 \pm 0.8$ \\
\hline Response to basic therapy & $8.7 \pm 1.2$ & Unsatisfactory \\
\hline AST-test & Unsatisfactory & $12.1 \pm 1.9$ \\
\hline Use of oral steroids per week & $11.8 \pm 1.5$ & $4.5 \pm 0.9$ \\
\hline Use of peroral steroids per week & $4.3 \pm 0.8$ & $2.2 \pm 1.1$ \\
\hline Night symptoms per week & $2.1 \pm 0.9$ & $4.2 \pm 0.9$ \\
\hline
\end{tabular}

Note: ${ }^{*}<<0.05$

Table III. AQLQ Quality of Life Assessment in Dynamics of observation

\begin{tabular}{ccccc}
\hline & \multicolumn{3}{c}{ Groups } \\
\cline { 2 - 5 } Scale & \multicolumn{3}{c}{ Main group } & \multicolumn{2}{c}{ Comparison group } \\
\cline { 2 - 5 } & $\mathbf{1}^{\text {st }}$ visit & $\mathbf{1 5}^{\text {th }}$ visit & $\mathbf{1}^{\text {st }}$ visit & $\mathbf{1 5}^{\text {th }}$ visit \\
\hline Activity & $3.7 \pm 0.1^{*}$ & $5.8 \pm 0.2$ & $3.6 \pm 0.2$ & $3.6 \pm 0.3$ \\
\hline Symptoms & $3.5 \pm 0.3$ & $5.2 \pm 0.8$ & $3.5 \pm 0.1$ & $3.6 \pm 0.2$ \\
\hline Emotions & $3.6 \pm 0.1^{*}$ & $5.4 \pm 0.4$ & $3.5 \pm 0.5$ & $3.4 \pm 0.2$ \\
\hline Environment & $3.4 \pm 0.2$ & $4.9 \pm 0.8$ & $3.4 \pm 0.3$ & $3.5 \pm 0.1$ \\
\hline General life quality & $3.5 \pm 0.1^{*}$ & $5.7 \pm 0.2$ & $3.5 \pm 0.2$ & $3.5 \pm 0.1$ \\
\hline
\end{tabular}

Note: ${ }^{*} p<0.05$

using Spearman and Pearson correlation coefficients.

The study was conducted with the written consent of the patient and with the requirements of bioethics.

\section{RESULTS AND DISCUSSION}

Presently, patients with comorbid pathology in the form of EBW or obesity have been found to have a more uncontrolled course of BA, which has a lower response to the baseline therapy.

Our study confirms this hypothesis, so it was found that the majority of the patients in the main group and the comparison group who had uncontrolled asthma had EBW or obesity by the design of the study, namely $41.03 \%$ of patients in both groups, and 32 patients had comorbid pathology as obesity and $41.03 \%$ of patients had EBW.

At the same time, it should be noted that a number of studies indicate gender differences in the incidence of obesity or EBW, in our study we also confirm this, so it was found that the main group included 27 women and the comparison group -25 . That is, the majority of patients with uncontrolled asthma against the background of EBW or obesity are women.

During history taking it was found that patients with uncontrolled course of asthma had comorbid pathology not only in the form of EBW or obesity, but also hypertension in 37 patients (47.43\%), gastroesophageal disease in 33 patients (42.31\%), chronic obstructive disease of the lungs was found in 7 patients $(8.97 \%)$, and diabetes was diagnosed in 2 patients.

At the first visit, all patients were asked to complete a quality of life questionnaire (AQLQ (BA quality of life)). The data received are presented in the Table I.

Table 1 shows that patients with uncontrolled BA have low quality of life scores and no statistically reliable difference between groups. 


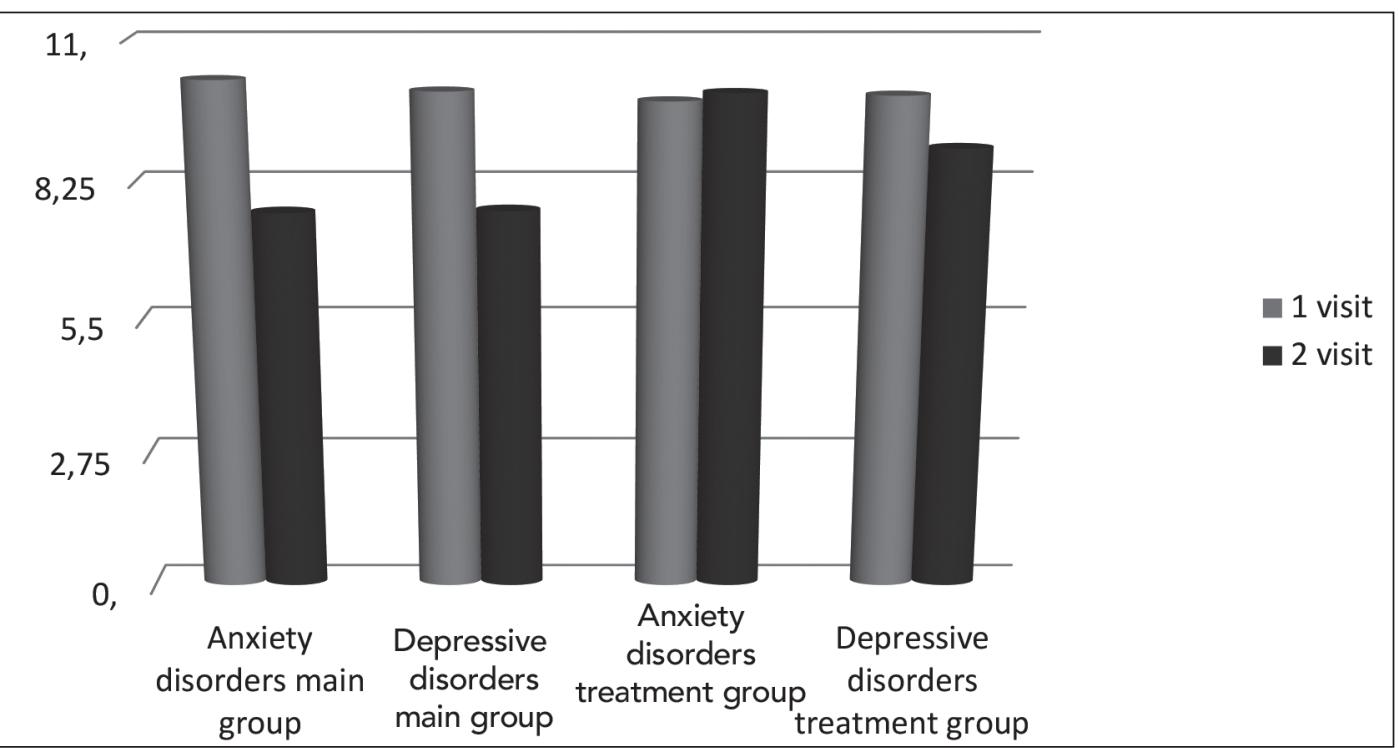

Fig 2. Dynamics of the HADS scale in the patients with uncontrolled asthma against the background of EBW or overweight.

Manifestations of anxiety-depressive disorders (ADD) were detected in $44(56.41 \%)$ patients in the main group. At the same time clinically expressed ADD by the HADS scale in the main group were observed in $35.89 \%$ of patients, subclinically expressed in $20.51 \%$ (mean score 21.7 \pm 1.4 and $9.4 \pm 1.2$, respectively).

Together with the above questionnaires, the patients also answered questions on the disease course and symptom control. The data are presented in the Table II.

According to the design of the study, the patients in the main group were offered CBT together with baseline therapy, which included 15 sessions, and the patients in the comparison group who refused the proposed therapy received only baseline treatment.

It should be noted that all patients in the main group willingly attended CPT sessions and improved compliance with the attending physician. The patients were motivated to change attitudes toward their underlying disease, namely, asthma, and were strongly encouraged to lose weight in those patients who had comorbid abnormalities such as EBW or obesity.

According to the design of the study, the feasibility of using CBT in the patients with uncontrolled course of asthma against the background of EBW or obesity was based of a number of criteria, the first one was the AQLQ questionnaire (Table III).

Table III shows that the patients in the main group had reliable positive dynamics in a number of indices, namely emotions, activity, overall quality of life $(\mathrm{p} \leq 0.05)$. Such indices as symptoms and the environment also gained positive dynamics, however, when statistically calculated, they did not have reliable indices $(\mathrm{p} \geq 0.05)$, whereas the comparison patients receiving only baseline therapy had no significant changes in the quality of life in BA.

The patients of the main group had positive dynamics in overcoming anxiety and depressive disorders. These indices, according to the study design were diagnosed using

\section{the HADS scale (Fig. 2)}

Fig. 2 shows that patients in the main group had reliable positive dynamics in overcoming ADD, namely from 10.23 \pm 0.81 points anxiety disorders acquired $7.65 \pm 0.98$ points after CBT, and depressive ones changed from $10.01 \pm 0.79$ points to $7.69 \pm 0.67$ points by the HADS scale $(p \leq 0.05)$. The patients in the treatment group receiving baseline therapy had no reliable changes in ADD by the HADS scale $(\mathrm{p} \geq 0.05)$.

Cognitive-behavioral therapy also had a positive effect on the course and control of the disease, namely the patients in the main group began to use rescue medications less frequently, and FABD per week reduced from $8.7 \pm 1.2$ at the first visit to $5.1 \pm 0.9$ at the 15 th visit $(p \leq 0.05)$. The number of such threatening predictors as the amount of nocturnal symptoms per week decreased, at the first visit patients noted $4.3 \pm 0.5$ and there were $3.1 \pm 0.3$ nocturnal attacks of asthma at the 15 th visit $(\mathrm{p} \leq 0.05)$. The patients who had undergone CPT improved asthma control, namely by the result of the AST test, which was $15.6 \pm 1.1$ points at the 15 th visit versus $11.8 \pm 1.5$ at the first visit. All of the above changes are related to the primary group, the comparison group patients did not have any change, and even 7 patients experienced worsening of the underlying disease.

As for changes in the treatment of asthma in the patients of the main group and the comparison group, no positive dynamics were recorded regarding the response to the baseline therapy during the period of the follow-up, and it remained unsatisfactory. However, the patients in the main group who underwent CBT in addition to basic treatment reduced the use of oral and peroral steroids 1.5-2 times, whereas the patients in the comparison group did not obtain such results.

\section{CONCLUSIONS}

1. Bronchial asthma with comorbid pathology in the form of excess body weight and obesity has a more severe and 
uncontrolled course, which complicates the patient's treatment with baseline therapy.

2. Patients with uncontrolled bronchial asthma have a low standard of life quality according to the AQLQ questionnaire, and the majority of patients, namely $56.41 \%$, have anxiety disorders by the HADS scale.

3. The use of cognitive - behavioral therapy has a positive effect on certain indices of the AQLQ questionnaire $(p \leq 0.05)$ and has a positive effect on the patient's psychological state, namely, reduces the manifestations of anxiety and depression $(\mathrm{p} \leq 0.05)$ in patients with uncontrolled asthma.

4. Cognitive-behavioral therapy improves the course of uncontrolled bronchial asthma in a number of indices, namely reducing the frequency of use of short-acting $\beta$-2-agonists, nocturnal symptoms of asthma, the amount of oral and peroral steroids used.

5. The additional use of cognitive-behavioral therapy in patients with uncontrolled bronchial asthma against the background of excess body weight or obesity has a positive effect on asthma control according to the results of the AST test $(\mathrm{p} \leq 0.05)$. Cognitive-behavioral therapy should be obligatory in routine practice for physicians managing patients with bronchial asthma.

\section{REFERENCES}

1. Global Initiative for Asthma. Global Strategy for Asthma Management and Prevention, 2016. Link: https://ginasthma.org/wp-content/ uploads/2016/04/GINA-Appendix-2016-final.pdf (actually on 15.11.19)

2. The Global Asthma Report 2014. Auckland, NewZealand: Global Asthma Network, 2014.Link: http://www.globalasthmanetwork.org/ publications/Global_Asthma_Report_2014.pdf(actually on 15.11.19)

3. Asthma UK. Stress and anxiety. Link: https://www.asthma.org.uk/ advice/triggers/stress/ (actually on 15.11.19)

4. British guideline of the management of asthma. A national clinical guideline. 2014. Link: https://www.brit-thoracic.org.uk > asthma > btssign-asthma-guideline-2014 (actually on 15.11.19)

5. Zielinski T, Brown E, Nejtek V et al. Depression in asthma: prevalence and clinical implications. PrimCareCompanion J. ClinPsychiatry. 2000; 2(5): 153-158.

6. Ettinger A, Reed M, Cramer J. Depression and comorbidity in communitybased patients with epilepsy or asthma. Neurology. 2004;63 (6): 1008-1014.

7. Heaney L, Robinson D. Severe asthma treatment: need for characterizing patients. Lancet. 2005; 365 (9463): 974-976.

8. Katon W, Richardson L, Lozano P et al. The relationship of asthma and anxiety disorders. PsychosomMed. 2004; 66 (3): 349-55.

9. Tashiro H, Shore S. Shore Obesity and severe asthma. Allergol Int. 2019; 68 (2):135-142. doi: https://doi.org/10.1016/j.alit.2018.10.004.

10. Baffi C, Winnica D, Holguin F. Asthma and obesity: mechanisms and clinical implications. AsthmaResPract. 2015;1: 1. doi: 10.1186/ s40733015-0001-7.

11. Mohanan S, Tapp H, McWilliams A et al. Obesity and asthma: Pathophysiology and implications for diagnosis and management in primary care. ExpBiolMed (Maywood). 2014; 239 (11):1531-1540.doi: 10.1177 / 1535370214525302

12. FDA Drug Safety Communication: New safety requirements for longacting inhaled asthma medications called Long-Acting Beta-Agonists (LABAs). US Food, DrugAdministration. 2010.
13. Why asthma still kills: the National Review of AsthmaDeaths (NRAD) Confidential Enquiry report. Royal College of Physicians. London: RCP, 2014,115. Link: https://www.asthma.org.uk/globalassets/campaigns/ nrad-full-report.pdf (actually on 15.11.19).

14. Cognitive behavioural therapy. Royal College of Psychiatrists. Link: www. rcpsych.ac.uk/mentalhealthinfoforall/treatments/cbt.aspx (actually on 15.11.19).

15. Kew K, Nashed M, Dulay V, Yorke J. Cognitive behavioral therapy (CBT) for adults and adolescents with asthma. Cochrane DatabaseSystRev. 2016;9:CD011818. doi: 10.1002 / 14651858.CD011818.pub2

16. Cognitive - behavioral psychotherapy. Link: https://en.wikipedia.org/ wiki/Cognitive-behavioral psychotherapy (actually on 15.11.19).

17. Moffitt R, Haynes A, Mohr P. Treatment beliefs and preferences for psychological therapies for weight management. J. ClinPsychol. 2015; 71 (6): 584-596.

18. Wilson G, Wilfley D, Agras W et al. Psychological treatments for bingeeating disorder. ArchGenPsychiatry. 2010; 67 (1): 94-101.

19. Grillo C, Masheb R, Wilson G et al. Cognitive-behavioral therapy, behavioral weight loss, and sequential treatment for obese patients with binge-eating disorder: a randomized controlled trial. J. ConsultClinPsychol. 2011; 79 (5): 675-685.

20. Reas D, Grilo C. Review and meta-analysis of pharmacotherapy for binge-eating disorder. Obesity (SilverSpring) 2008; 16 (9): 2024-2038.

21. Wilson G, Grilo C, Vitousek. Psychological treatment of eating disorders. AmPsychol. 2007; 62 (3): 199-216.

22. DalleGrave R, Centis E, Marzocchi R. et al. Major factors for facilitating change in behavioral strategies to reduce obesity. PsycholResBehavManag. 2013; 6: 101-110.

The material of the article is a fragment of the research work of the Ministry of Health of Ukraine and the Department of Family Medicine and General Practice of Odessa National Medical University "Age-specific features of treatment and rehabilitation of pulmonary, endocrinological diseases in patients with overweight in the practice offamily doctor" (№ state registration 0115U006645).

\section{ORCID and contributionship:}

Yana I. Bazhora - 0000-0002-7622-0750 A,B,C,D,E,F

\section{Conflict of interest:}

The Author declare no conflict of interest

\section{CORRESPONDING AUTHOR Yana I. Bazhora \\ Odessa National Medical University \\ Valikhovsky Lane 2, 0desa, 65028, Ukraine \\ tel: +380674891155 \\ e-mail:yana19_91@ukr.net}

Received: 10.09 .2019

Accepted: 18.12 .2019

A - Work concept and design, B - Data collection and analysis, C - Responsibility for statistical analysis,

D-Writing the article, $\mathbf{E}$-Critical review, $\mathbf{F}$ - Final approval of the article 